\title{
Development of a Chinese version of the National Eye Institute Visual Function Questionnaire (CHI-VFQ-25) as a tool to study patients with eye diseases in Hong Kong
}

\author{
C W S Chan, ${ }^{1}$ D Wong, ${ }^{1}$ C L K Lam, ${ }^{2}$ S McGhee, ${ }^{3}$ W W Lai ${ }^{1}$
}

\begin{abstract}
${ }^{1}$ Eye Institute, The University of Hong Kong, Pokfulam, Hong Kong; ${ }^{2}$ Department of Medicine (FMU), The University of Hong Kong, Pokfulam, Hong Kong; ${ }^{3}$ Department of Community Medicine, The University of Hong Kong, Pokfulam, Hong Kong
\end{abstract}

Correspondence to: Dr W W Lai, The Eye Institute The University of Hong Kong, Room 301, Block B, Cyberport 4, 100 Cyberport Road, Hong Kong: wicolai@hku.hk

Accepted 25 May 2009 Published Online First 9 June 2009

\section{ABSTRACT}

Background: To develop a Chinese version of the National Eye Institute Visual Function Questionnaire (CHIVFO-25) and to test its reliability and validity in a group of patients with eye diseases in Hong Kong.

Methods: The National Eye Institute Visual Function Questionnaire (NEI-VFO) was translated into Chinese. Patients were recruited from Hong Kong, and their demographic data and visual acuity were documented. Psychometric properties of the CHI-VFO-25, including internal consistency, test-retest reliability, item-scale correlations and construct validity were tested.

Results: 250 patients were recruited. The mean age of the patients was 66.04 (SD 14.00). $46 \%$ of them were male. The non-response rate and the floor and ceiling numbers of the CHI-VFO-25 were calculated. The internal consistency was high in most subscales (except the general health and driving subscales), with Cronbach $\alpha$ ranging from $0.72-0.90$. The test-retest reliability was excellent (intraclass correlation coefficient $>0.90$ ). Patients with worse visual acuity had significantly lower scores on the CHI-VFO-25 supporting construct validity. Conclusion: The CHI-VFO-25 is a reliable and valid tool for assessing the visual functions of Chinese patients with eye diseases in Hong Kong. Some questions had high non-response rates and should be substituted by the available alternatives.

Visual function questionnaires (VFO) have increasingly been used to measure the impact of diseases and the outcomes of treatment. The National Eye Institute Visual Function Questionnaire (NEIVFO) has been widely used to study the visual functions of patients with cataract, glaucoma, agerelated macular degeneration, diabetic retinopathy and retinal detachment. ${ }^{1-5}$ To date, the English, Spanish, French, Italian, Japanese and Turkish versions of the NEI-VFO are available. ${ }^{6-11}$

Research activities in the life sciences during the past few years have increased appreciably in China, both in output and in impact. Although several Chinese VFO are available, most have not been validated ${ }^{12}{ }^{13}$ and none were universally adopted. ${ }^{14-}$ ${ }^{16}$ The widespread adoption of a validated questionnaire would add to the rigor of ophthalmic research and, if this was a Chinese version of the NEI-VFO, would also facilitate the international comparison of results of clinical trials.

The purpose of this study was to evaluate the psychometric properties of the NEI-VFQ translated into Chinese (CHI-VFO-25) and tested on Chinese ophthalmic patients. We used all the supplementary questions and selected those that were most suitable for ethnic Chinese patients.

\section{METHODS}

Two hundred and fifty patients were recruited from the Department of Ophthalmology, Queen Mary Hospital, Hong Kong between May 2008 and July 2008. Based on Snellen visual acuity measurements, the patients were divided into two groups, group A (with a presenting visual acuity of worse than 20/60) and group B (with a presenting visual acuity of $20 / 60$ or better). All visual acuities were measured by an optometrist with patients wearing their own glasses (if applicable). We aimed to measure presenting vision, and so no refraction or pin-hole vision was used. Eligible participants had to be at least 18 years old, Chinese speaking and without any cognitive impairment. Patients were enrolled consecutively into either group until the target number was achieved. This study was approved by the Institutional Review Board of the University of Hong Kong and adhered to the tenets of the Declaration of Helsinki.

After obtaining informed consent, patients' basic demographics including age, gender, education level, the nature of eye disease and other comorbidities were recorded. A subgroup of patients, $20 \%$ from each group, was selected randomly to return in 2 weeks for retesting.

\section{Twenty-five-Item National Eye Institute Visual Function Questionnaire (NEI-VF0-25)}

The NEI-VFO-25 consists of 11 vision-related domains and one general health rating question. It also includes additional items that can expand the NEI-VFQ-25 into a 39-item questionnaire. The 11 vision-related subscales include: general vision, difficulty with near and distance activities, driving difficulties, limitations with peripheral and colour vision, ocular pain, social functioning, role limitations, dependency and mental health. The NEIVFO-25 is scored using standard algorithms. Higher scores indicate better visual functions. ${ }^{17}$

\section{Development of CHI-VFO-25}

The development of CHI-VFO-25 involved six steps:

1. Translation of the NEI-VFO-25 from English to Chinese was done by two professional translators. 
2. Reconciliation of the Chinese translations was done by a panel to produce a second draft of CHI-VFQ-25.

3. A third translator, who was not involved in the forward translation and blinded to the original questionnaire, backtranslated the drafted CHI-VFQ-25 into English.

4. The back-translated CHI-VFO-25 was compared with the original English version to identify any discrepancies, which was then revised by the panel.

5. Cognitive debriefing of the drafted CHI-VFQ-25 was performed on five people with visual impairment to test their understanding and interpretation of the questionnaire.

6. The final version of the CHI-VFO-25 was established after minor revisions, taking into account the outcome of the cognitive debriefing.

\section{Statistical analysis}

Descriptive statistics were used to determine the distribution of demographic and clinical characteristics. The percentage of item response at the ceiling (highest possible score) and floor (lowest possible score) and the number of non-response items (not doing the suggested activity for reasons other than visual problem) of the CHI-VFQ-25 were also calculated.

Internal consistency (Cronbach $\alpha$ ) is a measure of the extent to which items within a single subscale correlate with each other. The optimal range of Cronbach $\alpha$ is $0.70-0.90$. To further determine scale homogeneity, the item-scale correlation coefficient was calculated. A coefficient greater than 0.40 is considered acceptable. ${ }^{18}$

A subgroup of patients was retested after 2 weeks to determine the test-retest reliability (intraclass correlation coefficient) of the questionnaire. The time point was set at 2 weeks as this was short enough to avoid changes in visual acuity and long enough for patients not to remember the answers. Reliability coefficients above 0.70 are considered satisfactory. ${ }^{6}$

Construct validity was determined by comparing the CHIVFO-25 scores from the two groups of patients. Patients with worse visual acuity should have lower scores on the CHI-VFO25.

All analyses were conducted at the 5\% significance level, using SPSS version 16.0 (SPSS, Chicago).

\section{RESULTS}

The mean time required to complete the CHI-VFQ-25 was 10.83 (SD 3.81) min. The mean age of the 250 participants was 66.04 (14.00); 115 (46\%) were male. Patients in group A were significantly older, were less well educated and had more coexisting medical conditions (table 1).

\section{Item analysis}

The percentages of non-response items and responses at the floor and ceiling of each subscale are shown in table 2.

Items in the driving subscale had the highest non-response rate. One hundred per cent of participants in group A and $90 \%$ in group $B$ did not respond. Items related to going out to watch movies, plays or sporting events had the next highest nonresponse rate at $70 \%$ in group $\mathrm{A}$ and $52 \%$ in group B. Items associated with literacy also had higher rates (about 20\%) than other items in the CHI-VFQ-25.

Floor effect was not found in any of the subscales. However, the percentage of subjects scoring at the ceiling was over $20 \%$ in five out of 12 subscales (ocular pain, social functioning, dependency, colour vision and peripheral vision).

Table 1 Demographic characteristics of study participants

\begin{tabular}{|c|c|c|c|c|}
\hline & Group A & Group B & Total & p Value* \\
\hline Age (mean (SD)) & $73.48(9.00)$ & $58.61(14.26)$ & $66.04(14.00)$ & 0.001 \\
\hline$<50$ & $2(1.6)$ & $29(23.2)$ & $31(12.4)$ & \\
\hline $50-59$ & $10(8.0)$ & $35(28.0)$ & $45(18.0)$ & \\
\hline $60-69$ & 18 (14.4) & $30(24.0)$ & 48 (19.2) & \\
\hline $70-79$ & $58(46.4)$ & $26(20.8)$ & $84(33.6)$ & \\
\hline$\geqslant 80$ & $37(29.6)$ & $5(4.0)$ & $42(16.8)$ & \\
\hline Gender & & & & 0.703 \\
\hline Male & $59(47.2)$ & 56 (44.8) & $115(46.0)$ & \\
\hline Female & $66(52.8)$ & $69(55.2)$ & $135(54.0)$ & \\
\hline Education & & & & 0.000 \\
\hline No schooling & $64(51.2)$ & $26(20.8)$ & $90(36.0)$ & \\
\hline Primary & $33(26.4)$ & $20(16.0)$ & $53(21.2)$ & \\
\hline Secondary & $25(20.0)$ & $60(48.0)$ & $85(34.0)$ & \\
\hline Tertiary & $3(2.4)$ & $19(15.2)$ & $22(8.8)$ & \\
\hline No of comorbidities & & & & 0.002 \\
\hline 0 & $17(13.6)$ & $40(32.0)$ & $57(22.8)$ & \\
\hline 1 & $45(36.0)$ & $45(36.0)$ & $90(36.0)$ & \\
\hline 2 & $40(32.0)$ & $28(22.4)$ & $68(27.2)$ & \\
\hline$\geqslant 3$ & $23(18.4)$ & $12(9.6)$ & $35(14.0)$ & \\
\hline Principal diagnosis & & & & $<0.001$ \\
\hline Age-related macular degeneration & $8(6.4)$ & $11(8.8)$ & $19(7.6)$ & \\
\hline Cataract & $29(23.2)$ & $54(43.2)$ & $83(33.2)$ & \\
\hline Diabetic retinopathy & 14 (11.2) & 23 (18.4) & 37 (14.8) & \\
\hline Glaucoma & $4(3.2)$ & $5(4.0)$ & $9(3.6)$ & \\
\hline Retinal detachment & $21(16.8)$ & $7(5.6)$ & $28(11.2)$ & \\
\hline Others & 49 (39.2) & $25(20.0)$ & $74(29.6)$ & \\
\hline
\end{tabular}

With the exception of age, data are expressed as the number of subjects, with the percentage of the total group in parentheses. *Probabilities are from the $\chi^{2}$ test (categorical variables) contrasting group $\mathrm{A}$ and group $\mathrm{B}$ patients. 
Table 2 Results of item-scale correlation, number and percentage of non-response data, floor number and ceiling number

\begin{tabular}{|c|c|c|c|c|}
\hline Subscale and item & $\begin{array}{l}\text { Item-scale } \\
\text { correlation }\end{array}$ & $\begin{array}{l}\text { Non-response } \\
\text { no }(\%)\end{array}$ & Floor no $(\%)$ & Ceiling no $(\%)$ \\
\hline General Health & & & $3(1.2)$ & 0 \\
\hline 5-level health rating & 0.86 & 0 & & \\
\hline $0-10$ health rating & 0.87 & 0 & & \\
\hline General Vision & & & 0 & 0 \\
\hline 6-level vision rating & 0.86 & 0 & & \\
\hline $0-10$ vision rating & 0.89 & 0 & & \\
\hline Ocular Pain & & & 0 & $88(35.2)$ \\
\hline Amount of pain & 0.90 & 0 & & \\
\hline Amount of time in pain & 0.89 & 0 & & \\
\hline Near Activities & & & 0 & $19(7.6)$ \\
\hline Reading ordinary print in newspaper & 0.87 & $55(22.0)$ & & \\
\hline Seeing well up close & 0.77 & $12(4.8)$ & & \\
\hline Finding objects on crowded shelf & 0.73 & $4(1.6)$ & & \\
\hline Reading small print & 0.84 & $51(20.4)$ & & \\
\hline Reading bills accurately & 0.74 & $57(22.8)$ & & \\
\hline Shaving/styling hair/makeup & 0.36 & $7(2.8)$ & & \\
\hline Distance Activities & & & 0 & $28(11.2)$ \\
\hline Reading street signs/names of stores & 0.83 & 0 & & \\
\hline Going down stairs at night & 0.79 & $12(4.8)$ & & \\
\hline Going out to watch movies/plays/sporting events & 0.84 & $153(61.2)$ & & \\
\hline Recognising people from across a room & 0.58 & 0 & & \\
\hline $\begin{array}{l}\text { Taking part in active sports/other outdoor } \\
\text { activities }\end{array}$ & 0.60 & $59(23.6)$ & & \\
\hline Watching television & 0.83 & $5(2.0)$ & & \\
\hline Social Functioning & & & 0 & $114(45.6)$ \\
\hline Seeing how people react & 0.74 & $1(0.4)$ & & \\
\hline Visiting others/parties/going to restaurants & 0.93 & $23(9.2)$ & & \\
\hline Entertaining friends and family at home & 0.65 & $55(22.0)$ & & \\
\hline Dependency & & & $7(2.8)$ & $85(34.0)$ \\
\hline Amount true: stay home most of the time & 0.86 & 0 & & \\
\hline Amount true: reply on others & 0.84 & 0 & & \\
\hline Amount true: need help from others & 0.85 & 0 & & \\
\hline Mental Health & & & 0 & $24(9.6)$ \\
\hline Amount of time: worry & 0.53 & 0 & & \\
\hline Amount true: frustrated & 0.83 & 0 & & \\
\hline Amount true: no control & 0.75 & 0 & & \\
\hline Amount true: embarrassed & 0.73 & 0 & & \\
\hline Amount true: irritated & 0.77 & 0 & & \\
\hline Role Difficulties & & & $1(0.4)$ & $33(13.2)$ \\
\hline Accomplish less & 0.80 & 0 & & \\
\hline Limited in endurance & 0.75 & 0 & & \\
\hline Receive more help from others & 0.75 & 0 & & \\
\hline Limited in things can do & 0.83 & 0 & & \\
\hline Colour Vision & & & 0 & $222(88.8)$ \\
\hline Difficulty in matching clothes & 1.00 & 0 & & \\
\hline Peripheral Vision & & & 0 & $145(58.0)$ \\
\hline Seeing objects off to side & 1.00 & $2(0.8)$ & & \\
\hline Driving & & & 0 & $3(1.2)$ \\
\hline Familiar places during daytime & 0.50 & $238(95.2)$ & & \\
\hline Driving at night & 0.73 & $238(95.2)$ & & \\
\hline Driving under difficult condition & 0.87 & $239(95.6)$ & & \\
\hline
\end{tabular}

\section{Correlation}

The item-scale correlations coefficients were generally high, ranging from 0.50 to 0.93 (table 2). Only one item in the "near activity" subscale (difficulty with shaving/styling hair/putting on makeup) had a correlation coefficient less than 0.40 .

\section{Reliability}

Cronbach $\alpha$ of the CHI-VFQ-25 ranged from 0.50 to 0.90 . Except for the general health and driving subscales, Cronbach $\alpha$ values were greater than or equal to 0.70 (table 3 ). Test-retest reliability was high, with an intraclass correlation coefficient above 0.90 in all subscales (table 3 ).

\section{Construct validity}

After controlling for age and education level, patients in group A had lower marks in all subscales than that of group B. The differences were statistically significant, except for general health, ocular pain, colour vision and peripheral vision 
Table 3 Internal consistency (Cronbach $\alpha$ ) and test-retest reliability of CHI-VFQ-25 subscales

\begin{tabular}{lll}
\hline Subscale & Cronbach $\boldsymbol{\alpha}$ & Test-retest reliability \\
\hline General Health & 0.50 & 0.97 \\
General Vision & 0.73 & 0.96 \\
Ocular Pain & 0.74 & 0.95 \\
Near Activities & 0.84 & 0.96 \\
Distance Activities & 0.90 & 0.95 \\
Social Functioning & 0.72 & 0.96 \\
Mental Health & 0.81 & 0.98 \\
Role Difficulties & 0.81 & 0.98 \\
Dependency & 0.81 & 0.97 \\
Driving & 0.68 & $\mathrm{NA} \dagger$ \\
Colour Vision & $\mathrm{NA}^{*}$ & 0.92 \\
Peripheral Vision & $\mathrm{NA}^{*}$ & 0.92 \\
\hline
\end{tabular}

${ }^{*}$ Cronbach $\alpha$ cannot be calculated in subscales with only one item.

$\dagger$ Too few cases $(\mathrm{N}=1)$ ) for the analysis.

NA, not applicable.

(tables 4, 5). No participant in group A drove. Therefore, the construct validity of the driving subscale cannot be estimated.

\section{DISCUSSION}

Visual loss has been found to have a negative impact on quality of life $e^{2-41920}$ and was ranked second to paralysis as the most feared disability by the Chinese. ${ }^{21}$ Traditionally, the success or failure of medical therapy for eye diseases has been judged by meeting an objective criterion, such as visual acuity. However, there are disparities between ophthalmologists and their patients in estimating the benefit of treatment because clinical examinations do not evaluate patient's perceptions of their own diseases. ${ }^{22}$ Thus, a vision-specific questionnaire is needed to study how visual impairment affects patients' subjective physical and psychosocial well-being.

We successfully translated the NEI-VFO into Chinese and evaluated its psychometric properties in a group of patients with visual impairment. Overall, we found that the CHI-VFO25 has psychometric properties comparable with those of the original version and is a reliable and valid tool for assessing the visual functions of Chinese patients.

We suggest making several changes. Compared with the original version, the non-response rate was very much higher in the driving subscale. Almost all participants did not drive. A high non-response rate in this subscale was also found in the Japanese (61\%) and French versions (34\%). ${ }^{810}$ Therefore, we suggest that the "driving" subscale should be omitted in the CHI-VFO-25.

Going out to watch movies, plays or sporting events also had a high non-response rate, especially in older patients. Over twothirds of participants aged 60 or above did not participate in these activities, while only two-fifths of participants below the age of $60 \mathrm{did}$ not respond. Although a high non-response rate was also found in the Japanese version, the percentage was much lower than that of the Chinese version (32\% vs $61 \%) .{ }^{10}$ Participants either think that the tickets were too expensive or were not interested in those activities. We suggest substituting this question with another question in the appendix (difficulty when watching and enjoying programmes on TV).

Of note are the questions related to literacy, which also had a higher rate of missing data than those in the French $(0 \%)$ and Japanese $(2-12 \%)$ versions of the NEI-VFO. ${ }^{8} 10$ In our population, where most were 70 years or older, $36 \%$ did not receive any education. This lack of formal education might be related to the few schools available before and after the Second World War and the relative poverty in the region at that time. The inability of many patients to recognise the letters of the alphabet meant that we could not use the ETDRS chart. We employed a Snellen Chart with roman numerals for this study, and we are validating a logMAR chart using numbers for future studies.

The reliability of CHI-VFO-25 was satisfactory in all subscales except for the general health and driving subscales. The Cronbach $\alpha$ values were slightly lower than those of the US version, ${ }^{6}$ but were similar or better than those of other translations. ${ }^{7-11}$

The low reliability of the driving subscale was probably due to the high non-response rate. However, the low Cronbach $\alpha$ for the general health subscale suggest that the subscale constructs were not homogenous. In rating the general health, participants

Table 4 Construct validity of the Chinese version of the National Eye Institute Visual Function Questionnaire (CHI-VFO-25) in group A and group B patients in different age groups

\begin{tabular}{|c|c|c|c|c|c|c|c|c|c|c|c|}
\hline & \multicolumn{5}{|l|}{ Group A } & \multicolumn{5}{|l|}{ Group B } & \multirow[b]{2}{*}{ p Value* } \\
\hline & $<\mathbf{5 0}$ & $50-59$ & $60-69$ & 70-79 & $\geqslant 80$ & $<\mathbf{5 0}$ & $50-59$ & $60-69$ & $70-79$ & $\geqslant 80$ & \\
\hline $\begin{array}{l}\text { General } \\
\text { Health }\end{array}$ & $42.5(7.1)$ & $40.8(15.0)$ & $40.1(11.8)$ & $42.2(19.7)$ & $42.7(16.1)$ & $51.7(18.2)$ & $50.6(17.3)$ & $45.2(14.0)$ & 42.5 (18.6) & $37.5(26.5)$ & 0.277 \\
\hline General Vision & $45.0(0.0)$ & $48.0(21.1)$ & $40.8(11.0)$ & $46.8(14.4)$ & $47.4(14.5)$ & $65.7(13.4)$ & $64.6(14.4)$ & $56.3(11.1)$ & $56.5(13.5)$ & $55.0(7.1)$ & 0.001 \\
\hline Ocular Pain & $81.3(26.5)$ & $67.5(23.7)$ & $69.4(28.8)$ & $74.4(24.0)$ & $82.8(21.3)$ & $79.3(18.7)$ & 83.2 (19.9) & $76.3(21.1)$ & $72.1(26.5)$ & $90.0(10.5)$ & 0.269 \\
\hline $\begin{array}{l}\text { Near } \\
\text { Activities }\end{array}$ & $68.8(26.5)$ & $57.3(25.4)$ & $52.6(23.1)$ & $60.2(24.4)$ & $58.5(25.0)$ & $86.6(15.9)$ & $77.3(14.5)$ & 76.6 (18.7) & 70.5 (18.2) & $70.8(22.1)$ & 0.001 \\
\hline $\begin{array}{l}\text { Distance } \\
\text { Activities }\end{array}$ & $62.5(35.4)$ & $65.6(22.9)$ & $60.4(22.1)$ & $65.9(19.4)$ & $62.2(26.1)$ & $89.0(13.0)$ & $85.8(15.1)$ & $84.6(15.8)$ & $75.3(19.7)$ & $85.3(18.2)$ & 0.001 \\
\hline $\begin{array}{l}\text { Social } \\
\text { Functioning }\end{array}$ & $83.3(23.6)$ & $70.0(23.0)$ & $66.2(25.4)$ & $72.3(24.2)$ & $73.0(27.0)$ & $94.8(12.3)$ & $93.8(14.8)$ & $92.1(13.0)$ & $89.6(14.2)$ & $93.3(14.9)$ & 0.001 \\
\hline Mental Health & $87.5(17.7)$ & $61.0(32.1)$ & $55.8(24.3)$ & $64.1(26.4)$ & $60.4(28.6)$ & $82.8(13.7)$ & $83.3(14.5)$ & $78.8(21.8)$ & $66.9(29.6)$ & $73.0(29.7)$ & 0.024 \\
\hline $\begin{array}{l}\text { Role } \\
\text { Difficulties }\end{array}$ & $71.9(13.3)$ & $71.3(20.0)$ & $57.6(27.8)$ & $61.1(22.5)$ & $53.9(27.9)$ & $82.3(14.2)$ & $83.9(17.2)$ & $77.1(17.1)$ & $65.4(19.2)$ & $81.3(13.3)$ & 0.001 \\
\hline Dependency & $100.0(0.0)$ & $70.0(26.5)$ & $66.7(26.3)$ & $57.1(25.5)$ & $51.4(29.1)$ & $96.1(7.7)$ & $94.8(13.3)$ & $87.3(17.0)$ & $70.2(28.6)$ & $82.5(22.3)$ & 0.001 \\
\hline Colour Vision & $100.0(0.0)$ & $95.0(10.5)$ & $88.9(23.0)$ & $94.0(17.7)$ & $92.6(21.1)$ & $100.0(0.0)$ & $97.1(8.1)$ & $99.2(4.6)$ & $93.3(16.7)$ & $100.0(0.0)$ & 0.210 \\
\hline $\begin{array}{l}\text { Peripheral } \\
\text { Vision }\end{array}$ & $100.0(0.0)$ & $72.5(24.9)$ & $79.2(24.6)$ & $79.7(24.5)$ & $74.3(28.1)$ & $94.8(14.0)$ & $87.9(17.5)$ & $86.7(19.4)$ & $86.5(21.5)$ & $85.0(22.4)$ & 0.121 \\
\hline Composite & $80.0(14.3)$ & $67.8(18.3)$ & $63.8(16.1)$ & $67.6(15.1)$ & $65.5(18.3)$ & 87.2 (8.8) & $85.2(11.0)$ & $81.5(11.1)$ & $74.6(14.3)$ & $81.6(8.4)$ & 0.001 \\
\hline
\end{tabular}

Composite is the average subscale scores excluding the general health subscale. The Driving subscale was omitted, as there were too few cases for analysis.

*Probabilities are from univariate analysis of variance contrasting group A and group B patients in different age groups. 
Table 5 Construct validity of the Chinese version of the National Eye Institute Visual Function Questionnaire (CHI-VFQ-25) in group A and group B patients with different education levels

\begin{tabular}{|c|c|c|c|c|c|c|c|c|c|}
\hline & \multicolumn{4}{|l|}{ Group A } & \multicolumn{4}{|l|}{ Group B } & \multirow[b]{2}{*}{ p Value* } \\
\hline & No schooling & Primary & Secondary & Tertiary & No schooling & Primary & Secondary & Tertiary & \\
\hline $\begin{array}{l}\text { General } \\
\text { Health }\end{array}$ & $39.7(16.8)$ & $43.3(15.6)$ & $44.4(18.3)$ & $52.5(28.4)$ & $39.5(17.8)$ & $47.0(16.2)$ & $47.9(16.3)$ & $47.4(17.7)$ & 0.390 \\
\hline $\begin{array}{l}\text { General } \\
\text { Vision }\end{array}$ & $45.9(12.9)$ & $45.3(17.7)$ & $47.4(14.7)$ & $53.3(11.6)$ & $53.3(14.4)$ & $60.3(11.8)$ & $62.2(12.7)$ & $67.4(13.1)$ & 0.001 \\
\hline Ocular Pain & $74.8(24.4)$ & 77.7 (19.7) & $75.5(29.2)$ & $75.0(33.1)$ & $76.0(21.2)$ & $81.9(20.9)$ & $77.9(22.2)$ & $80.9(20.6)$ & 0.434 \\
\hline $\begin{array}{l}\text { Near } \\
\text { Activities }\end{array}$ & $56.3(25.2)$ & $60.2(23.0)$ & $60.6(24.5)$ & $70.8(21.7)$ & $68.6(19.6)$ & $78.3(15.8)$ & 77.8 (17.4) & $88.6(10.6)$ & 0.001 \\
\hline $\begin{array}{l}\text { Distance } \\
\text { Activities }\end{array}$ & $60.5(22.2)$ & $67.8(22.2)$ & $65.5(20.7)$ & $80.6(26.8)$ & $74.3(19.1)$ & $89.8(15.0)$ & $84.9(15.6)$ & $88.7(11.1)$ & 0.001 \\
\hline $\begin{array}{l}\text { Social } \\
\text { Functioning }\end{array}$ & $65.4(26.8)$ & 77.2 (21.9) & $78.2(20.3)$ & $87.5(21.7)$ & $85.6(17.2)$ & $96.3(6.3)$ & $92.6(14.3)$ & $99.1(3.8)$ & 0.001 \\
\hline $\begin{array}{l}\text { Mental } \\
\text { Health }\end{array}$ & $58.4(27.7)$ & $68.2(24.7)$ & $62.8(29.4)$ & $61.7(18.9)$ & $65.8(27.8)$ & $85.0(20.2)$ & 78.8 (19.2) & $86.8(8.7)$ & 0.001 \\
\hline $\begin{array}{l}\text { Role } \\
\text { Difficulties }\end{array}$ & $58.6(24.1)$ & $58.1(25.8)$ & $64.5(25.3)$ & $50.0(34.8)$ & $69.0(18.6)$ & $85.9(13.3)$ & $78.1(18.3)$ & $81.3(16.1)$ & 0.001 \\
\hline Dependency & $52.1(26.8)$ & $61.6(27.3)$ & $70.3(27.2)$ & $64.6(3.6)$ & $68.8(28.4)$ & $93.1(9.3)$ & $90.9(10.3)$ & $97.7(7.3)$ & 0.001 \\
\hline Colour Vision & $89.8(23.0)$ & $97.7(7.3)$ & $94.0(18.1)$ & $100.0(0.0)$ & $94.2(16.3)$ & $98.8(5.6)$ & $97.9(7.0)$ & $100.0(0.0)$ & 0.408 \\
\hline $\begin{array}{l}\text { Peripheral } \\
\text { Vision }\end{array}$ & $74.2(26.8)$ & $83.3(24.7)$ & $78.0(23.2)$ & $91.7(14.4)$ & $81.7(21.9)$ & $91.3(18.6)$ & $90.0(17.4)$ & $92.1(14.6)$ & 0.097 \\
\hline Composite & $63.5(16.1)$ & $69.7(16.1)$ & $69.7(16.8)$ & $73.5(14.9)$ & 73.7 (13.6) & $86.1(9.0)$ & $83.1(11.7)$ & $88.2(6.1)$ & 0.001 \\
\hline
\end{tabular}

Composite is the average subscale scores excluding the general health subscale. The Driving subscale was omitted, as there were too few cases for analysis

*Probabilities are from univariate analysis of variance contrasting group A and group B patients with different education levels.

were asked to choose from "excellent," "very good," "good," "fair" or "poor" in question 1. Most participants rated their general health as "fair," which corresponded to 25 marks. When they were asked to rate their general health in the appendix on a scale of $0-10$ ( 0 is as poor as death, and 10 is excellent health), those who rated "fair" had scores ranging from 0 to 10 (which corresponded to 0 to 100 marks), indicating a low homogeneity. Therefore, we suggest substituting the five-level general health rating (question 1 ) with the $0-10$ rating scale in the appendix for our Chinese participants.

All subscales had intraclass correlation coefficients greater than 0.90, indicating that the CHI-VFO-25 has excellent testretest reliability.

The item-scale correlations were satisfactory. Most items showed similar or slightly poorer correlations when compared with those in the US version. ${ }^{6}$ Only one item in the "near activities" subscale (difficulties with shaving/styling/putting on makeup) showed a poor correlation with its corresponding subscale.

After controlling for age and education level, the CHI-VFQ-25 was able to discriminate between patients with good and poor visual acuities with the exception in the subscales of general health, ocular pain, colour vision and peripheral vision. The lack of difference in the general health subscale between the two groups was expected, as it was not a vision-related subscale. However, the lack of a significant difference in ocular pain, colour vision and peripheral vision subscales was probably due to the fact that the majority of patients had diseases that were less affected in these areas. Similar findings were also found in previous studies. $^{911}$

It is important to consider the following limitations when interpreting the results of this study. Visual acuity was the only factor we considered for the loss of vision. However, other clinical measurements, such as contrast sensitivity, ${ }^{23}$ visual field ${ }^{2}$ and glare,$^{24}$ may affect visual functions independently. Second, the responsiveness of the questionnaire (the change in visual functions after treatment) was not assessed in our study. We also only studied two groups. This therefore limits the conclusion that we can draw from the study as to whether it can discriminate between minimally and significantly reduced vision. A larger study involving segregation of patients into disease groups and more accurate measurement of visual acuity together with other parameters such as contrast sensitivity might enable us to better define the relationship between the VFQ and visual function. Lastly, all the patients were recruited from a single hospital, and they might not represent the whole population in Hong Kong.

Acknowledgements: The authors would like to thank the Research Centre of Heart, Brain, Hormone and Healthy Aging (HBHA), The University of Hong Kong for their support in this study.

Funding: This study is supported in part by the Seed Funding Program and the University Development Fund, LKS Faculty of Medicine, The University of Hong Kong.

Competing interests: None.

Ethics approval: Ethics approval was provided by Institutional Review Board, The University of Hong Kong.

Patient consent: Obtained.

Provenance and peer review: Not commissioned; externally peer reviewed.

\section{REFERENCES}

1. Espindle D, Crawford B, Maxwell A, et al. Quality-of-life improvements in cataract patients with bilateral blue light-filtering intraocular lenses: clinical trial. J Cataract Refract Surg 2005;31:1952-9.

2. McKean-Cowdin R, Wang Y, Wu J, et al. Impact of visual field loss on healthrelated quality of life in glaucoma: the Los Angeles Latino Eye Study. Ophthalmology 2008;115:941-8.

3. Lotery A, Xu X, Zlatava G, et al. Burden of illness, visual impairment and health resource utilisation of patients with neovascular age-related macular degeneration: results from the UK cohort of a five-country cross-sectional study. $\mathrm{Br} \mathrm{J}$ Ophthalmol 2007;91:1303-7.

4. Klein R, Moss SE, Klein BE. The NEI-VFO-25 in people with long-term type 1 diabetes mellitus: the Wisconsin Epidemiologic Study of Diabetic Retinopathy. Arch Ophthalmol 2001;119:733-40.

5. Okamoto F, Okamoto $Y$, Hiraoka $T$, et al. Vision-related quality of life and visual function after retinal detachment surgery. Am J Ophthalmol 2008;146:85-90.

6. Mangione CM, Lee PP, Pitts J, et al. Psychometric properties of the National Eye Institute Visual Function Questionnaire (NEI-VFO). Arch Ophthalmol 1998;116:1496-504. 
7. Broman AT, Munoz B, West SK, et al. Psychometric properties of the 25-item NEI-VFO in a Hispanic population: Proyecto VER. Invest Ophthalmol Vis Sci 2001;42:606-13.

8. Nordmann JP, Viala M, Sullivan K, et al. Psychometric validation of the National Eye Institute Visual Function Questionnaire-25 (NEI VFQ-25) French version: in a population of patients treated for ocular hypertension and glaucoma. Pharmacoeconomics 2004;22:197-206.

9. Rossi GC, Milano G, Tinelli C. The Italian version of the 25-item National Eye Institute Visual Function Questionnaire: translation, validity, and reliability. J Glaucoma 2003;12:213-20.

10. Suzukamo Y, Oshika T, Yuzawa M, et al. Psychometric properties of the 25-item National Eye Institute Visual Function Questionnaire (NEI VFQ-25), Japanese version. Health Oual Life Outcomes 2005;3:65.

11. Toprak AB, Eser E, Guler C, et al. Cross-validation of the Turkish version of the 25item National Eye Institute Visual Functioning Questionnaire (NEI-VFO 25). Ophthalmic Epidemiol 2005;14:259-69.

12. $\mathbf{H e} \mathbf{M}, \mathrm{Xu} \mathrm{J}$, Li S, et al. Visual acuity and quality of life in patients with cataract in Doumen County, China. Ophthalmology 1999;106:1609-15.

13. Saw SM, Tseng P, Chan WK, et al. Visual function and outcomes after cataract surgery in a Singapore population. $J$ Cataract Refract Surg 2002;28:445-53.

14. Dam OM, Sibley LM, Law FC, et al. Reliability and reproducibility of a Chineselanguage visual function assessment. Ophthalmic Epidemiol 2001;8:327-37.

15. Chan WN, Wong JC, Chan KS, et al. Evaluation of quality of life in patient with cataract in Hong Kong. J Cataract Refract Surg 2003;29:1753-60.
16. Zou H, Zhang $\mathrm{X}, \mathrm{Xu} \mathrm{X}$, et al. Development and psychometric tests of the Chineseversion low vision quality of life questionnaire. Oual Life Res 2005;14:1633-9.

17. Mangione CM. The National Eye Institute 25-Item Visual Function Questionnaire (VFQ-25), NEI VFQ-25 scoring algorithm—August 2000. http://www.nei.nih.gov/ resources/visionfunction/manual_cm2000.pdf (accessed 1 Nov 2007).

18. Globe D, Varma R, Azen SP, et al. Psychometric performance of the NEI VFQ-25 in visually normal Latinos: the Los Angeles Latino Eye Study. Invest Ophthalmol Vis Sci 2003;44:1470-8.

19. Clemons TE, Chew EY, Bressler SB, et al. National Eye Institute Visual Function Questionnaire in the Age-Related Eye Disease Study (AREDS): AREDS report no. 10 Arch Ophthalmol 2003;121:211-17.

20. Broman AT, Munoz B, Rodriguez $\mathrm{J}$, et al. The impact of visual impairment and eye disease on vision-related quality of life in a Mexican-American population: Proyecto VER. Invest Ophthalmol Vis Sci 2002;43:3393-8.

21. Lau JTK, Lee V, Fan D, et al. Attitudes towards and perceptions of visual loss and its causes among Hong Kong Chinese adults. Clin Exp Ophthalmol 2004;32:243-50.

22. Stein JD. Disparities between ophthalmologists and their patients in estimating quality of life. Curr Opin Ophthalmol 2004;15:238-43.

23. Datta S, Foss AJ, Grainage MJ, et al. The importance of acuity, stereopsis, and contrast sensitivity for health related quality of life in elderly women with cataracts. Invest Ophthalmol Vis Sci 2008:49:1-6.

24. Saw SM, Gomezperalta C, Au-Eong KG, et al. Utility assessment among cataract surgery patients. J Cataract Refract Surg 2005;31:785-91. 